\title{
Émissions d'oxyde nitreux lors du traitement de l'azote des eaux usées de l'agglomération parisienne : état actuel et prévisions
}

\section{Nitrous oxide emissions during the removal of nitrogen from wastewater treatment plants in the Paris metropolitan area: current state and forecasts}

\author{
Gaëlle Tallec, Olivier Rousselot, Josette Garnier et Michel Gousailles
}

Volume 20, numéro 1, 2007

URI : https://id.erudit.org/iderudit/015742ar

DOI : https://doi.org/10.7202/015742ar

\section{Aller au sommaire du numéro}

\section{Éditeur(s)}

Université du Québec - INRS-Eau, Terre et Environnement (INRS-ETE)

\section{ISSN}

1718-8598 (numérique)

Découvrir la revue

Citer cet article

Tallec, G., Rousselot, O., Garnier, J. \& Gousailles, M. (2007). Émissions d'oxyde nitreux lors du traitement de l'azote des eaux usées de l'agglomération parisienne : état actuel et prévisions. Revue des sciences de l'eau / Journal of Water Science, 20(1), 149-161. https://doi.org/10.7202/015742ar

\section{Résumé de l'article}

La Seine, un des fleuves les plus anthropisés d'Europe, reçoit les rejets des eaux usées de près de quinze millions d'habitants, soit le quart de la population française, dont dix millions sont concentrés dans l'agglomération parisienne. Suite à la directive européenne 91/271, l'assainissement des eaux usées de l'agglomération parisienne est actuellement remodelé et amélioré. Les flux d'azote, rejetés auparavant en Seine, seront progressivement traités via des procédés basés sur des cultures libres (boues activées) ou fixées (biofiltres immergés) permettant la nitrification et la dénitrification de la pollution azotée.

Néanmoins, il est désormais admis que de l'oxyde nitreux $\left(\mathrm{N}_{2} \mathrm{O}\right)$, un gaz à effet de serre destructeur de la couche d'ozone, pourrait être émis dans l'atmosphère de façon significative durant le traitement biologique de l'azote en station d'épuration (STEP). Ces émissions ont été quantifiées en fonction des charges en azote traitées et des procédés utilisés, en conditions expérimentales. En se basant sur ces résultats, nous avons évalué les émissions de $\mathrm{N}_{2} \mathrm{O}$ sur l'ensemble des stations d'épuration de l'agglomération parisienne, dans les conditions actuelles des traitements pratiqués, mais également estimé les émissions futures, suite aux principaux changements prévus aux horizons 2006-2008 et 2012-2015.

Les estimations conduisent à des émissions actuelles de $\mathrm{N}_{2} \mathrm{O}$ de l'ordre de 60-120 kg N-N $\mathrm{N}_{2} \mathrm{O} / \mathrm{j}$, qui augmenteront à l'issue de la première étape des travaux (2006-2008) à 320-480 kg N-N ${ }_{2} \mathrm{O} / \mathrm{j}$, pour atteindre $370-750 \mathrm{~kg} \mathrm{~N}-\mathrm{N}_{2} \mathrm{O} / \mathrm{j}$ en 2012-2015. Les niveaux les plus bas de ces émissions pourraient être atteints si le traitement de l'azote se fait avec une oxygénation supérieure à $2 \mathrm{mgO}_{2} / \mathrm{L}$ en nitrification et en dénitrification, avec des conditions d'anoxie totales et un ajout de méthanol permettant $100 \%$ de la réduction de la charge en nitrate.

Compte tenu de nos résultats pour les stations d'épuration $\left(60-120 \mathrm{~kg} \mathrm{~N}-\mathrm{N}_{2} \mathrm{O} / \mathrm{j}\right)$ et ceux obtenus pour la Seine à l'aval du rejet des effluents non traités pour l'azote (90-200 kg N-N $\left.{ }_{2} \mathrm{O} / \mathrm{j}\right)$, les émissions actuelles de $\mathrm{N}_{2} \mathrm{O}$ sont estimées à 150-320 kg $\mathrm{N}-\mathrm{N}_{2} \mathrm{O} / \mathrm{j}$, et celles du futur augmenteraient d'un facteur d'à peine 2 quand le traitement de l'azote sera complet en stations d'épuration; cette augmentation est relativement faible si l'on tient compte de la gamme de nos estimations. De plus, à l'échelle du bassin de la Seine, les émissions d'oxyde nitreux liées au traitement de l'azote dans les stations d'épuration de l'agglomération parisienne (actuel et futur) continueront de représenter une faible proportion, de 1 à $10 \%$ par rapport aux émissions provenant des sols agricoles du bassin amont $\left(4100-8200 \mathrm{~kg} \mathrm{~N}-\mathrm{N}_{2} \mathrm{O} / \mathrm{j}\right)$. 


\title{
ÉMISSIONS D'OXYDE NITREUX LORS DU TRAITEMENT DE L'AZOTE DES EAUX USÉES DE L'AGGLOMÉRATION PARISIENNE : ÉTAT ACTUEL ET PRÉVISIONS
}

\author{
Nitrous oxide emissions during the removal of nitrogen from wastewater treatment plants in the Paris metropolitan \\ area: current state and forecasts
}

\author{
Gaëlle Tallec ${ }^{1,2 *}$, Olivier Rousselot', Josette Garnier ${ }^{2}$ et Michel Gousailles' \\ ${ }^{1} S L A A P$ / DRD, 82, Av. Kléber, 92700 Colombes, France. \\ ${ }^{2}$ UMR Sisyphe 7619, Fonctionnement des Hydrosystèmes, Université P. et M. Curie-CNRS, Boite 105, Tour 56, Étage 4, 4 place Jussieu, \\ 75005 Paris, France.
}

Reçu le 15 décembre 2005, accepté le 6 septembre 2006

\section{RÉSUMÉ}

La Seine, un des fleuves les plus anthropisés d'Europe, reçoit les rejets des eaux usées de près de quinze millions d'habitants, soit le quart de la population française, dont dix millions sont concentrés dans l'agglomération parisienne. Suite à la directive européenne 91/271, l'assainissement des eaux usées de l'agglomération parisienne est actuellement remodelé et amélioré. Les flux d'azote, rejetés auparavant en Seine, seront progressivement traités via des procédés basés sur des cultures libres (boues activées) ou fixées (biofiltres immergés) permettant la nitrification et la dénitrification de la pollution azotée.

Néanmoins, il est désormais admis que de l'oxyde nitreux $\left(\mathrm{N}_{2} \mathrm{O}\right)$, un gaz à effet de serre destructeur de la couche d'ozone, pourrait être émis dans l'atmosphère de façon significative durant le traitement biologique de l'azote en station d'épuration (STEP). Ces émissions ont été quantifiées en fonction des charges en azote traitées et des procédés utilisés, en conditions expérimentales. En se basant sur ces résultats, nous avons évalué les émissions de $\mathrm{N}_{2} \mathrm{O}$ sur l'ensemble des stations d'épuration de l'agglomération parisienne, dans les conditions actuelles des traitements pratiqués, mais également estimé les émissions futures, suite aux principaux changements prévus aux horizons 2006-2008 et 2012-2015.

Les estimations conduisent à des émissions actuelles de $\mathrm{N}_{2} \mathrm{O}$ de l'ordre de 60-120 kg N-N $\mathrm{N}_{2} \mathrm{O} / \mathrm{j}$, qui augmenteront à l'issue de la première étape des travaux (2006-2008) à $320-480 \mathrm{~kg} \mathrm{~N}-\mathrm{N}_{2} \mathrm{O} / \mathrm{j}$, pour atteindre $370-750 \mathrm{~kg}$ $\mathrm{N}-\mathrm{N}_{2} \mathrm{O} / \mathrm{j}$ en 2012-2015. Les niveaux les plus bas de ces émissions pourraient être atteints si le traitement de l'azote se fait avec une oxygénation supérieureà $2 \mathrm{mgO}_{2} / \mathrm{L}$ en nitrification et en dénitrification, avec des conditions d'anoxie totales et un ajout de méthanol permettant $100 \%$ de la réduction de la charge en nitrate.

Compte tenu de nos résultats pour les stations d'épuration (60-120 kg N- $\left.\mathrm{N}_{2} \mathrm{O} / \mathrm{j}\right)$ et ceux obtenus pour la Seine à l'aval $\mathrm{du}$ rejet des effluents non traités pour l'azote $(90-200 \mathrm{~kg}$ $\mathrm{N}-\mathrm{N}_{2} \mathrm{O} / \mathrm{j}$ ), les émissions actuelles de $\mathrm{N}_{2} \mathrm{O}$ sont estimées à $150-320 \mathrm{~kg} \mathrm{~N}-\mathrm{N}_{2} \mathrm{O} / \mathrm{j}$, et celles du futur augmenteraient d'un facteur d'à peine 2 quand le traitement de l'azote sera complet en stations d'épuration; cette augmentation est relativement faible si l'on tient compte de la gamme de nos estimations.

*Auteur pour correspondance :

Téléphone : $\quad 33.1 .40 .96 .60 .43$

Télécopieur: 33.1.40.96.61.99

Courriel : gaelle_tallec@yahoo.fr

ISSN : 1718-8598

Revue des Sciences de l'Eau 20(1) (2007) 149-161 
De plus, à l'échelle du bassin de la Seine, les émissions d'oxyde nitreux liées au traitement de l'azote dans les stations d'épuration de l'agglomération parisienne (actuel et futur) continueront de représenter une faible proportion, de 1 à $10 \%$ par rapport aux émissions provenant des sols agricoles du bassin amont (4100-8200 kg N-N $2 \mathrm{O} / \mathrm{j})$.

Mots clés : émissions de $\mathrm{N}_{2} \mathrm{O}$, stations d'épuration, traitement de l'azote, agglomération parisienne, bassin de la Seine.

\section{SUMMARY}

The Seine, one of Europe's rivers most affected by intense human pressures, receives wastewater discharges from almost fifteen million inhabitants, equal to a quarter of the French population, among which ten million are concentrated in the Paris conurbation. In the framework of the European directive $91 / 271$, wastewater treatment in the Paris conurbation is being reorganized and improved. The nitrogen load, still discharged to the Seine River, will be gradually treated by fixed biological culture and activated sludge processes, allowing nitrification and denitrification of nitrogen pollution.

It is now accepted that nitrous oxide $\left(\mathrm{N}_{2} \mathrm{O}\right)$, a greenhouse gas that induces the destruction of stratospheric ozone, is emitted during biological nitrogen treatment in wastewater treatment plants (WWTPs) and may be a significant source to the atmosphere. These emissions have been quantified under experimental conditions, depending on the nitrogen load treated and the treatment used. These results have allowed the estimation of $\mathrm{N}_{2} \mathrm{O}$ emissions from all WWTPs in the Paris conurbation for present treatments and also for future conditions, with new treatments being scheduled in 2006-2008 and then in 2012-2015.

We estimate present $\mathrm{N}_{2} \mathrm{O}$ emissions to be $60-120 \mathrm{~kg}$ $\mathrm{N}-\mathrm{N}_{2} \mathrm{O} / \mathrm{d}$, which would increase to $320-480 \mathrm{~kg} \mathrm{~N}-\mathrm{N}_{2} \mathrm{O} / \mathrm{d}$ in $2006-2008$ and reach $370-750 \mathrm{~kg} \mathrm{~N}-\mathrm{N}_{2} \mathrm{O} / \mathrm{d}$ in $2012-2015$. The emission levels could be limited to the lower range of values if the nitrification of nitrogen were performed at an oxygenation level higher than $2 \mathrm{mg} \mathrm{O} / \mathrm{L}$ and if denitrification were performed under total anoxic conditions and with a methanol addition, allowing a $100 \%$ reduction of the nitrate load.

According to our results found for Paris WWTPs (60-120 kg $\mathrm{N}-\mathrm{N}_{2} \mathrm{O} / \mathrm{d}$ ) and those obtained in the lower Seine River, which receives effluents not treated for nitrogen $\left(90-200 \mathrm{~kg} \mathrm{~N}-\mathrm{N}_{2} \mathrm{O} /\right.$ d), $\mathrm{N}_{2} \mathrm{O}$ emissions amount to $150-320 \mathrm{~kg} \mathrm{~N}-\mathrm{N}_{2} \mathrm{O} / \mathrm{d}$. This increase of $\mathrm{N}_{2} \mathrm{O}$ emissions by a factor of less than 2 is a rather low value taking into account the range of our estimates.
Furthermore, at the scale of the Seine River basin, nitrous oxide emissions from nitrogen treatments in Paris conurbation WWTPs (at present or in the future) would continue to represent a low proportion, 1 to $10 \%$, in comparison with the emissions from agricultural lands (4100-8200 kg N-N 2 O/d).

Key words: $\mathrm{N}_{2} \mathrm{O}$ emissions, wastewater treatment plants, nitrogen treatment, Paris conurbation, Seine River basin.

\section{INTRODUCTION}

La Seine reçoit les rejets des eaux usées de près de quinze millions d'habitants, dont dix millions d'habitants résident dans l'agglomération parisienne. Si l'élimination de la pollution carbonée a été appliquée dans de nombreuses stations d'épuration d'eaux usées, conduisant ainsi à l'obtention d'un effluent de meilleure qualité et à la réduction de son impact sur le milieu récepteur, des efforts doivent actuellement porter sur le traitement de l'azote. L'azote constitue en effet un élément clé de l'eutrophisation de la zone côtière (BILLEN et al., 2001; CUGIER et al., 2005).

Le traitement de l'azote des eaux usées se fait le plus souvent par traitement biologique. Des bactéries nitrifiantes et dénitrifiantes sont cultivées, en culture libre (boues activées) ou culture fixée, et permettent l'oxydation de l'ammonium en nitrate (la nitrification) et la réduction du nitrate en diazote gazeux (inerte) émis dans l'atmosphère (la dénitrification). Toutefois, il est désormais admis que de l'oxyde nitreux $\left(\mathrm{N}_{2} \mathrm{O}\right)$ pourrait être produit de manière significative et émis dans l'atmosphère durant le traitement biologique de l'azote en station d'épuration (STEP) via la nitrification et la dénitrification, que ce soit en boues activées (HANAKI et al., 1990; HANAKI et al., 1992; TALLEC, 2005; TALLEC et al., 2006; ZHENG et al., 1994) ou en cultures fixées (KIM et al., 2004; TALLEC, 2005). En effet, l'oxyde nitreux est produit par les bactéries impliquées dans les processus de nitrification (GOREAU et al., 1980; POTH et FOCHT, 1985) et de dénitrification (KNOWLES, 1982) (Figure 1).

Le $\mathrm{N}_{2} \mathrm{O}$ est un gaz à effet de serre extrêmement efficace, son potentiel de réchauffement est 320 fois plus élevé que celui du dioxyde de carbone $\left(\mathrm{CO}_{2}\right)$. Il persiste très longtemps dans l'atmosphère (120 ans environ), (IPCC, 2000). De plus, lorsqu'il est rejeté dans l'atmosphère, il finit par se convertir en oxyde nitrique (NO), un gaz destructeur de la couche d'ozone $\left(\mathrm{O}_{3}\right)$ stratosphérique (BLIEFERT et PERRAUD, 2001). Ce gaz à effet de serre retient désormais l'attention de la communauté scientifique concernée par les changements climatiques globaux. Sa stabilisation aux niveaux actuels de 311-313 ppb nécessiterait une réduction des émissions anthropogéniques de plus de $50 \%$ (CITEPA, 2003). 


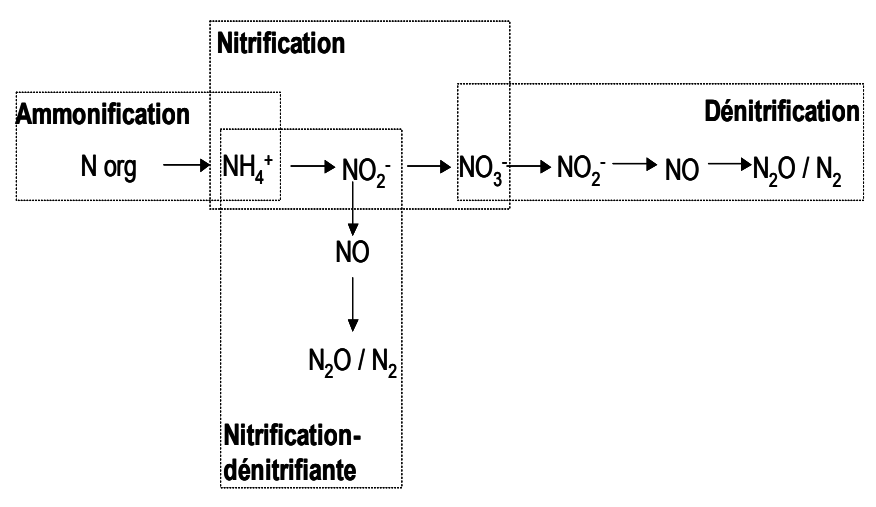

Figure 1. Processusbiologiques detransformation del'azote pouvant conduire à une production de $\mathrm{N}_{2} \mathrm{O}$ : la nitrification autotrophe, la nitrification dénitrifiante autotrophe et la dénitrification hétérotrophe. Ces processus peuvent intervenir en STEP aussi bien lors de l'élimination de l'ammonium que du nitrate.

Biological processes of nitrogen transformation producing $\mathrm{N}_{2} \mathrm{O}$ : autotrophic nitrification, autotrophic nitrifier denitrification and heterotrophic denitrification. These processes could occur in WWTP both during ammonium or nitrate removal.

Dans cette optique, à une échelle régionale, celle du bassin de la Seine, cette étude propose d'évaluer les émissions de ce gaz à effet de serre $\left(\mathrm{N}_{2} \mathrm{O}\right)$ afférentes à la nitrification et la dénitrification lors du traitement des eaux usées de l'agglomération parisienne. Alors que la nitrification et la dénitrification des eaux usées, y compris les émissions d'oxyde nitreux, se produisaient essentiellement dans la Seine, ces processus sont de plus en plus pris en charge, de manière accélérée et contrôlée, au niveau des stations d'épuration. Un des inconvénients majeurs serait une augmentation globale des émissions de $\mathrm{N}_{2} \mathrm{O}$ par le déplacement des sites d'émission, du milieu naturel vers les STEPs (GARNIER et al., 2006; ITOKAWA et al., 2001).

Un objectif majeur de cette étude est d'estimer les émissions de $\mathrm{N}_{2} \mathrm{O}$ actuelles pour l'ensemble des stations d'épuration de l'agglomération parisienne, compte tenu de leur type de traitement, en se basant sur des études expérimentales (cf. TALLEC, 2005); ces estimations sont comparées à un bilan effectué pour le bassin de la Seine (GARNIER et al., 2006). Un autre objectif est d'évaluer les émissions de $\mathrm{N}_{2} \mathrm{O}$ relatives aux futurs traitements de l'azote qui seront mis en place aux horizons 2006-2008 et 2012-2015, afin d'appréhender la quantité de pollution déplacée de la basse Seine, à l'aval des rejets de l'agglomération parisienne, vers les stations d'épuration de cette mégapole.

\section{LE BASSIN DE LA SEINE ET LES ÉMISSIONS DE $\mathrm{N}_{2} \mathrm{O}$}

\subsection{Le bassin de la Seine.}

Le réseau hydrographique de la Seine, qui prend sa source sur le plateau de Langres ( $417 \mathrm{~m}$ ) et se jette dans la Manche, s'étend sur un bassin versant de $78600 \mathrm{~km}^{2}$ (jusqu'au Havre). L'influence des mouvements de marée est perceptible jusqu'au barrage de Poses, limite artificielle de la Seine fluviale et estuarienne. Le réseau hydrographique de la Seine peut être subdivisé en quatre sous-bassins (la Seine amont et les affluents principaux de la Seine : Marne, Oise, Eure) et la basse Seine (Figure 2).

L'agriculture et l'élevage représentent les deux principales sources de pollution du bassin amont, tant au niveau des émissions de $\mathrm{N}_{2} \mathrm{O}$ dans l'atmosphère que des apports en nitrates au niveau du fleuve.

Les axes principaux des sous-bassins de la Seine, de la Marne et de l'Aube, sont équipés de barrages-réservoirs qui modifient à la fois l'hydrologie et la biogéochimie des cours d'eaux (GARNIER et al., 1999; 2000); ce sont des sites de sédimentation connus, qui entraînent le stockage ou l'élimination des éléments nutritifs $(\mathrm{Si}, \mathrm{N}, \mathrm{P})$. Ainsi, les nitrates diminuent grâce principalement au processus de dénitrification, mais les réservoirs étant situés en amont (Figure 2), la rétention de nitrates à l'échelle du bassin reste limitée (GARNIER et al., 2000).

L'urbanisation augmente surtout en aval de ces réservoirs. Certaines grosses agglomérations rejettent leurs effluents urbains (Troyes, Châlon-en-Champagne, Reims, etc.), les effets de ces rejets étant cependant beaucoup moins marqués que ceux de l'exutoire des grands axes et de la capitale, car les stations sont de bien plus faibles capacités (TUSSEAUVUILLEMIN et al., 2000).

Au niveau de la basse Seine, à l'aval de l'agglomération parisienne, la pollution ammoniacale représente une nuisance majeure. Depuis les années 1990, plusieurs travaux ont montré que l'azote ammoniacal (entre 1 et $4 \mathrm{mg} \mathrm{N} / \mathrm{L}$ ) apporté par les effluents de la station d'épuration Seine Aval (Achères, ouest de Paris), est complètement nitrifié au niveau de l'estuaire fluvial lors d'un transit de $200 \mathrm{~km}$ en aval, diminuant relativement peu sur le cours de la basse Seine (BRION et al., 2000; CÉBRON et al., 2003; GARNIER et al., 2001, 2006). Lactivité nitrifiante maximale dans l'estuaire entraîne une désoxygénation importante. Une étude a récemment montré que la nitrification de la colonne d'eau est accompagnée d'une émission de $\mathrm{N}_{2} \mathrm{O}$ notable, la dénitrification benthique 


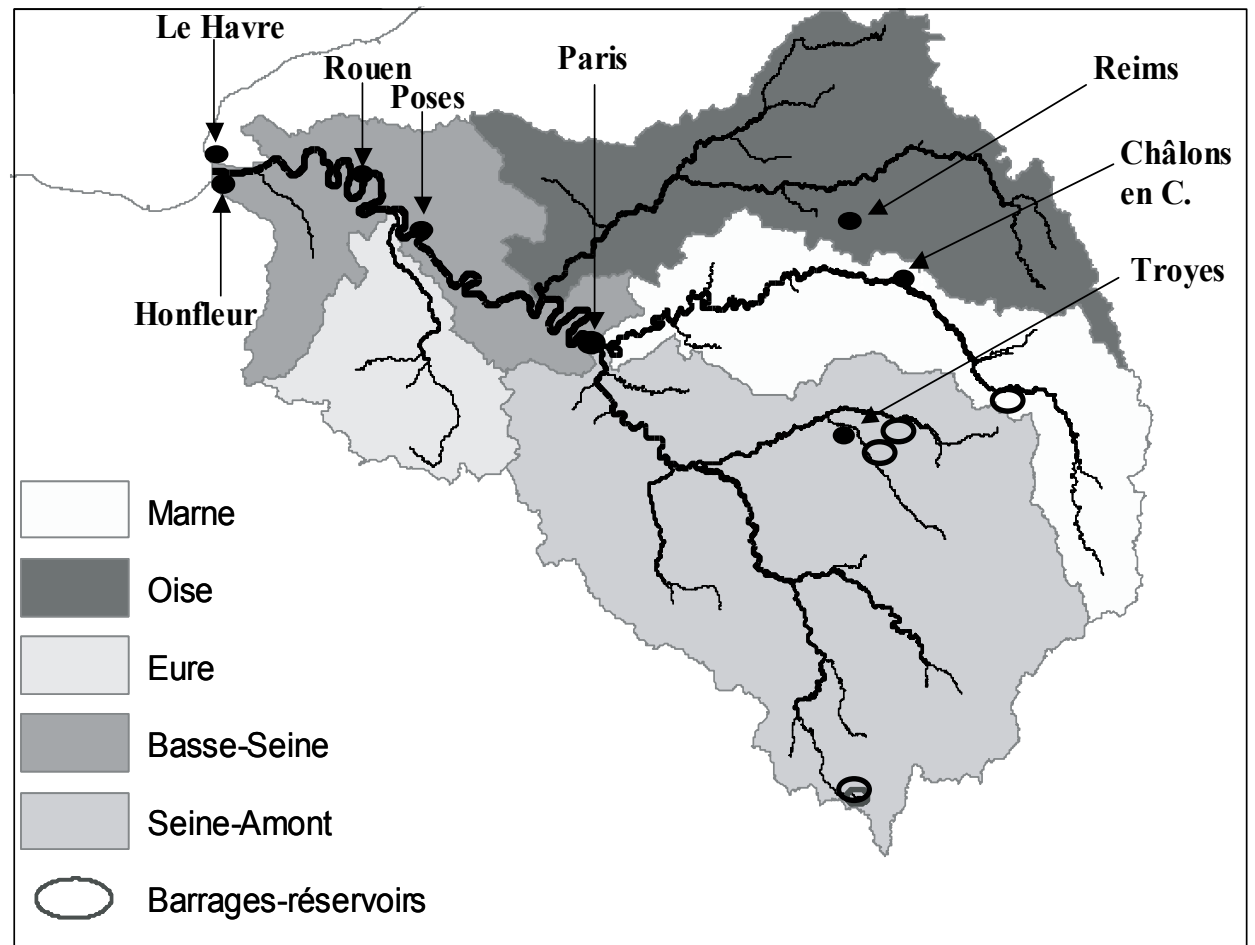

Figure 2. Carte représentant le réseau hydrographique de la Seine, ses quatre sous-bassins et la basse Seine (carte PIREN-Seine, S. Théry, comm. Pers.).

Map of the hydrographic network of the Seine River, its four sub-basins and the lower Seine River (PIREN-Seine map).

apparaissant aussi être une source de $\mathrm{N}_{2} \mathrm{O}$ (GARNIER et al., 2006; GARNIER et al., sous presse).

\subsection{Les émissions de $\mathrm{N}_{2} \mathrm{O}$ dans le bassin de la Seine.}

Des travaux sur les émissions de $\mathrm{N}_{2} \mathrm{O}$ sur l'ensemble du bassin de la Seine sont menés pour les différents secteurs du bassin. Avec le quart de la population française, dont dix millions en agglomération parisienne, et le tiers de la production agricole nationale, les principales zones de production $\mathrm{du} \mathrm{N}_{2} \mathrm{O}$ sur le bassin de la Seine sont le bassin amont agricole et la zone estuarienne (GARNIER et al., 2006). GARNIER et al. (2006) proposent en effet une gamme de $4100-8200 \mathrm{~kg}$ $\mathrm{N}-\mathrm{N}_{2} \mathrm{O} / \mathrm{j}$ pour le total des émissions de $\mathrm{N}_{2} \mathrm{O}$ provenant des sols agricoles du bassin de la Seine en amont de Poses, alors que pour le secteur de la basse Seine, de l'amont de Paris à l'estuaire fluvial, inclus, les émissions de $\mathrm{N}_{2} \mathrm{O}$ seraient en moyenne de $120 \mathrm{~kg} \mathrm{~N} / \mathrm{j}$ (90-200 kg N/j). En extrapolant à l'échelle du réseau hydrographique, les émissions de $\mathrm{N}_{2} \mathrm{O}$ observées sur les secteurs aval, GARNIER et al. (2006) proposent des valeurs de 370-680 kg N- $\mathrm{N}_{2} \mathrm{O} / \mathrm{j}$ pour l'ensemble des surfaces en eau de la Seine.

\section{LES STATIONS D'ÉPURATION DE L'AGGLOMÉRATION PARISIENNE ET LES ÉMISSIONS DE $\mathrm{N}_{2} \mathrm{O}$}

\subsection{Les stations d'épuration.}

Le Syndicat Interdépartemental pour l'Assainissement de l'Agglomération Parisienne (SIAAP), chargé de l'assainissement de la ville de Paris et des départements de la Petite Couronne (Hauts de Seine, Seine-Saint-Denis, Val de Marne), soit 10 millions d'habitants, exploite l'usine d'épuration "Seine Aval " ̀̀ Achères, "Marne Aval " à Noisy-le-Grand depuis 1976, "Seine Amont» à Valenton depuis 1987, "Seine Centre " à Colombes depuis 1998 et prochainement deux nouvelles stations, "Les Grésillons " fin 2006 et "La Morée " en 2015 (Figure 3).

\subsection{La station "Seine Aval»}

Achères, ouest de Paris, traite environ $20,8 \times 10^{5} \mathrm{~m}^{3} / \mathrm{j}$ en temps sec, soit les deux tiers des eaux usées de l'agglomération 


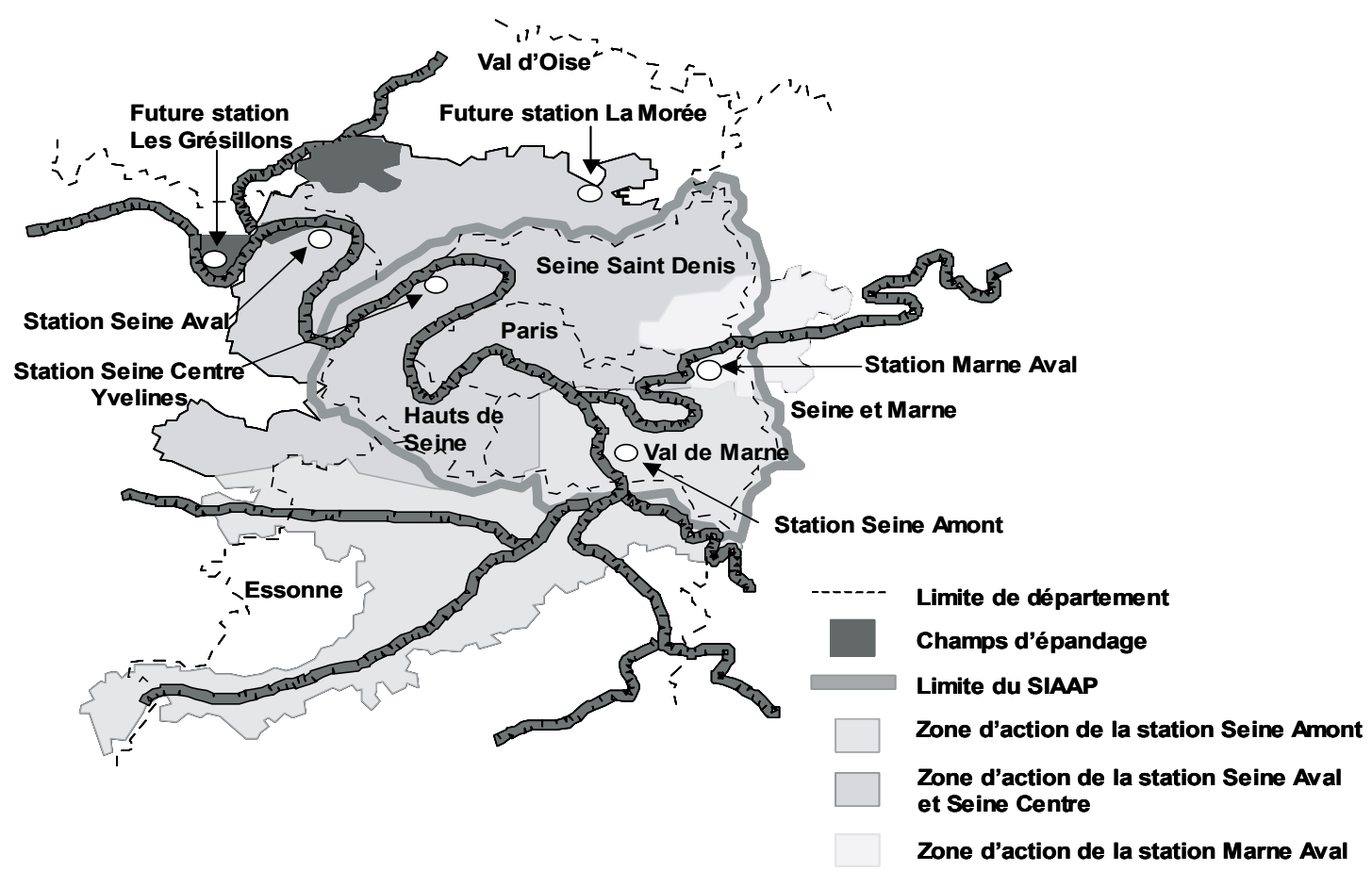

Figure 3. Zone de collecte du SIAAP (Syndicat Interdépartemental pour l'Assainissement de l'Agglomération Parisienne) et localisation des usines actuelles dont il a la charge; les futures stations sont également localisées.

Collection area of the SIAAP (Syndicat Interdépartemental pour l'Assainissement de l'Agglomération Parisienne) and location of the present wastewater treatment plants; the new ones planned in the future are also indicated.

parisienne, $69 \times 10^{5}$ équivalent habitant (éq. Hab.), via un traitement secondaire en boues activées.

Par temps sec, les eaux décantées primaires subissent une épuration biologique secondaire où seule la pollution carbonée est éliminée. Cette dernière s'effectue sur quatre tranches aux caractéristiques différentes. Une partie des eaux traitées biologiquement, subit une déphosphatation, basée sur un traitement physico-chimique ou "clarifloculation " (tamisage - coagulation-floculation - décantation).

Par temps de pluie, ce sont des eaux prétraitées qui arrivent au niveau de la clarifloculation où un traitement de la pollution carbonée et phosphorée est effectué.

\subsection{La station "Seine Centre "}

Colombes, ouest de Paris, d'une capacité de $2,4 \times 10^{5} \mathrm{~m}^{3} / \mathrm{j}$ ( $8 \times 10^{5}$ éq. Hab.), permet l'épuration des eaux allant jusqu'au traitement tertiaire par temps sec.

Le traitement s'effectue alors en trois étapes successives. L'eau brute, après un prétraitrement, une décantation physicochimique qui permet l'élimination des phosphates, subit une épuration biologique par biofiltres immergés (cultures fixées). Cette dernière permet selon les configurations de l'usine, fonction des conditions climatiques et du débit, l'abattement de la pollution carbonée et azotée. L'élimination de la pollution carbonée étant ici presque totale, du carbone organique exogène est ajouté (méthanol) pour activer la dénitrification.

Par temps de pluie, la station peut traiter jusqu'à $6,9 \times 10^{5} \mathrm{~m}^{3} / \mathrm{j}$, seule la pollution carbonée est alors éliminée. À titre d'exemple, en 2003 il y a eu environ une centaine de jours de pluie (arrêt annuel de la station compris).

\subsection{La station "Seine Amont "}

Valenton, est de Paris, traitera, fin 2006, $6 \times 10^{5} \mathrm{~m}^{3} / \mathrm{j}$ $\left(20 \times 10^{5}\right.$ éq. Hab.) via un traitement biologique secondaire en boues activées, opérant sur deux filières différentes de $3 \times 10^{5} \mathrm{~m}^{3} / \mathrm{j}$ chacune, Valenton I et Valenton II.

Sur Valenton I, l'eau décantée est introduite en tête des réacteurs biologiques cylindriques, dans la partie centrale anoxique, et chemine jusqu’à la zone aérobie externe. Seul le retour des boues activées extraites du clarificateur apporte la charge de nitrate au niveau de la zone anoxique. 
Sur Valenton II, l'eau décantée est introduite en tête du bassin biologique, caractérisé par une zone endogène et anaérobie pour l'élimination du phosphate, suivie d'une zone anoxique pour l'élimination du nitrate, puis d'une zone aérobie pour l'élimination de l'ammonium. La recirculation de la liqueur mixte, provenant de la partie aval de la zone aérobie, apporte le nitrate au niveau de la zone anoxique. Valenton II a ainsi un rendement épuratoire pour le nitrate plus important que Valenton I, soit $70 \%$ contre $50 \%$ respectivement.

Pour les deux systèmes, Valenton I et Valenton II, le carbone organique nécessaire aux bactéries hétérotrophes au niveau des bassins en anoxie est apporté par l'eau décantée.

\subsection{La station " Marne Aval»}

Noisy-Le-Grand, est de Paris, a une capacité nominale de $0,3 \times 10^{5} \mathrm{~m}^{3} / \mathrm{j}\left(1 \times 10^{5}\right.$ éq. Hab.).

Leau brute subit un pré-traitement, puis une décantation primaire. Une partie des eaux décantées passe ensuite dans un ouvrage d'activation biologique, composé de trois canaux. Le premier de ces canaux permet la réoxygénation des boues provenant du décanteur secondaire, dans le but de les réactiver, voire de les stabiliser. Les eaux épurées de la pollution carbonée rejoignent la deuxième partie des eaux décantées primaires, et passent en traitement tertiaire sur deux biofiltres à ruissellement $\left(\right.$ Sessil $\left.{ }^{\circ}\right)$ qui permettent la nitrification. Les eaux subissent ensuite un traitement physico-chimique (ajout de polymère et de chlorure ferrique) qui permet la déphosphatation.

Les quatre stations de l'agglomération parisienne en service actuellement présentent donc des stratégies de traitement de la pollution azotée, des débits et des rendements épuratoires différents (Tableau 1).

Le tableau 2 présente, pour chaque station, les flux d'ammonium et de nitrate entrants et rejetés actuellement.

Les flux d'ammonium entrants sont calculés à partir de moyennes annuelles des flux de l'azote Kjeldahl total (NTK) sur une période comprise entre 1993 et 2002 pour Seine Aval, 1999 à 2003 pour Seine Centre, 1994 à 2003 pour Marne Aval et de 1995 à 2002 pour Seine Amont. Le rapport $\mathrm{NH}_{4}^{+}$/ NTK utilisé pour les calculs est de 0,7 pour l'eau brute. Les valeurs exprimées en ammonium rejeté sont calculées suivant les rendements épuratoires par rapport au NTK de chaque station, excluant la station Seine Aval qui ne traite pas l'azote. Le rapport $\mathrm{NH}_{4}^{+} / \mathrm{NTK}$ utilisé pour les rejets est de 0,8 pour la station Seine Aval; les NTK y sont éliminés par ammonification en $\mathrm{NH}_{4}^{+}$lors de la décantation primaire, ce qui explique l'augmentation des flux d'ammonium sortants par rapport aux flux entrants. Pour les trois autres stations, nous avons utilisé un rapport $\mathrm{NH}_{4}^{+} / \mathrm{NTK}$ égal à 0,7 pour l'eau de rejet.

Pour les stations avec nitrification, les valeurs en nitrate entrant sont égales au flux de $\mathrm{NH}_{4}^{+}$traité en station lors de cette nitrification. Les valeurs de nitrate rejeté sont calculées à partir des rendements épuratoires fixés pour l'azote global (NGL) pour chaque station.

On confirme que les traitements sur Seine Aval, station la plus importante d'Europe, n'éliminent effectivement pas la pollution azotée. Si les autres stations de l'agglomération parisienne présentent un abattement de la pollution ammoniacale important, la pollution en nitrate reste importante. Seule la station Seine Centre présente actuellement des rejets en azote faibles. Rappelons que la directive européenne 91/271, et notamment la délimitation future du bassin de la Seine en zone sensible, devrait prochainement conduire à l'élimination de la pollution azotée au niveau de l'agglomération parisienne.

Seine Aval va être soulagée de $3 \times 10^{5} \mathrm{~m}^{3}$ de son débit journalier au profit de la station Seine Amont (Valenton II) à la fin de l'année 2006 . Un débit de $1 \times 10^{5} \mathrm{~m}^{3} / \mathrm{j}$ sera également acheminé à la nouvelle station des Grésillons dont la mise en route est prévue fin 2006 et dont le débit atteindra $3 \times 10^{5} \mathrm{~m}^{3} / \mathrm{j}$ en 2015 (Tableau 3). Enfin, l'usine Seine Aval traitera, sur cultures fixées en 2007, $80 \%$ de l'ammonium en nitrification et $33 \%$ (70 \% en 2015) en dénitrification (Tableau 3). À l'horizon 2006-2008, la station Marne Aval augmentera son débit de $0,5 \times 10^{5} \mathrm{~m}^{3} /$ japrès une restructuration de l'usine lui permettant de traiter $70 \%$ du NGL et $95 \%$ des NTK. La construction d'une nouvelle usine, la Morée, prévue en 2012-2015, permettra de traiter $0,5 \times 10^{5} \mathrm{~m}^{3} / \mathrm{j}$ (Tableau 3). Tous les systèmes de traitement prévus se feront majoritairement en traitement tertiaire sur cultures fixées. À noter qu'à l'horizon 2012-2015, l'abattement du NGL sur la station Seine Aval se fera bien sur cultures fixées, mais soit en traitement secondaire avec une recirculation ou en traitement tertiaire avec ajout de méthanol. Seule la station Seine Amont traitera l'azote en traitement secondaire en boues activées, du méthanol pouvant toutefois y être injecté si nécessaire pour atteindre les objectifs fixés de rejets.

Un tel traitement de la pollution azotée va contribuer à une modification considérable des flux d'azote traités via une nitrification et une dénitrification. À partir des flux de NTK et des rendements épuratoires, nous avons, comme précédemment, calculé les flux d'azote dans les conditions futures de nitrification et dénitrification (Tableau 4).

On remarque que les tonnages journaliers de $\mathrm{NH}_{4}^{+}$nitrifié $(\mathrm{N})$, relativement faibles actuellement $(18,2 \mathrm{~T} \mathrm{~N} / \mathrm{j}$, Tableau 4) 
Tableau 1. Débits, objectifs fixés pour les rendements épuratoires pour le NTK (azote Kjeldahl = azote organique $+\mathrm{NH}_{4}^{+}$) et le NGL (azote global $=\mathrm{NTK}+\mathrm{NO}_{3}^{-}+\mathrm{NO}_{2}^{-}$) et systèmes actuellement utilisés pour le traitement de l'azote sur les quatre stations d'épuration de l'agglomération parisienne. (* Traitement en temps sec; ${ }^{* *}$ Actuellement la réception des ouvrages de Valenton II étant en cours, seule la tranche de Valenton II fonctionne avec un débit de $\left.3 \times 10^{5} \mathrm{~m}^{3} / \mathrm{j}\right)$.

Table 1. Flows, targets set for the purification efficiencies for total Kjeldabl nitrogen (TKN) and global nitrogen (NGL), and current processes of nitrogen treatment used at the WWTPs of the Paris conurbation. ( Dry weather treatment; **at present, Valenton II is being delivered, only the sector of Valenton II is operated with an inflow of $\left.3 \times 10^{5} \mathrm{~m}^{3} / \mathrm{d}\right)$.

\begin{tabular}{|c|c|c|c|c|}
\hline & \multirow{2}{*}{$\begin{array}{l}\text { Débits } \\
\left(10^{5} \mathrm{~m}^{3} / \mathrm{j}\right)\end{array}$} & \multicolumn{2}{|c|}{ Rendement épuratoire } & \multirow[b]{2}{*}{ Systèmes utilisés } \\
\hline & & NTK & NGL & \\
\hline Seine Aval & 20,8 & 0 & 0 & Aucun \\
\hline Seine Centre * & 2,4 & 95 & 70 & Traitement tertiaire - Cultures fixées \\
\hline $\begin{array}{l}\text { Seine Amont** } \\
\text { Valenton I } \\
\text { Valenton II }\end{array}$ & 3 & $\begin{array}{l}95 \\
95\end{array}$ & $\begin{array}{l}50 \\
70\end{array}$ & Traitement secondaire - Boues activées \\
\hline Marne Aval & 0,3 & 75 & 0 & Traitement tertiaire - Cultures Fixées \\
\hline
\end{tabular}

Tableau 2. Flux actuels de l'ammonium et du nitrate entrants et rejetés, pour les quatre stations d'épuration de l'agglomération parisienne. (*Seuls les rendements épuratoires de Valenton I sont pris en compte ici).

Table 2. Present inflows and outflows of ammonium and nitrate, for the four WWTPs of the Paris conurbation. ( ${ }^{*}$ The treatment efficiencies of Valenton I only are reported here).

\begin{tabular}{lcccc}
\hline & $\mathbf{N H}_{4}{ }^{+}$entrant & $\mathbf{N H}_{4}{ }^{+}$rejeté & $\mathbf{N O}_{3}{ }^{-}$entrant & $\mathbf{N O}_{3}{ }^{-}$rejeté \\
\cline { 2 - 5 } & 56,1 & $\mathrm{~T} \mathrm{~N} / \mathbf{j}$ & 0 \\
\hline Seine Aval & 6,7 & 64,1 & 0 & 2,4 \\
Seine Centre & 0,4 & 6,3 & 7,6 \\
Seine Amont* & 11,5 & 0,6 & 10,9 & 1,0 \\
Marne Aval & 1,4 & 0,4 & $\mathbf{1 8 , 2}$ & $\mathbf{1 1}$ \\
Total & $\mathbf{7 5 , 7}$ & $\mathbf{6 5 , 5}$ & & \\
\hline
\end{tabular}

Tableau 3. Débits des effluents $\left(10^{5} \mathrm{~m}^{3} / \mathrm{j}\right)$, rendements épuratoires (Rdt. E en \%) pour le NGL et le NTK, total des débits traités et moyennes pondérées des Rdt. $\mathrm{E}$ (Moyp, par rapport aux débits) pour les stations d'épuration de l'agglomération parisienne (flux actuels et prévus aux horizons 2006-2008 et 2012-2015).

Table 3. Effluent flows $\left(10^{5} \mathrm{~m}^{3} / \mathrm{j}\right)$ and treatment efficiencies (Rdt. E in \%) for total Kjeldabl nitrogen (TKN) and global nitrogen (NGL), total of the treated flows and weighted average of Rdt. E (Moyp, related to the flows) for WWTPs of the Paris conurbation (present and future effluent flows as scheduled for 2006-2008 and 2012-2015).

\begin{tabular}{|c|c|c|c|c|c|c|c|c|c|}
\hline & \multicolumn{3}{|c|}{ Actuel } & \multicolumn{3}{|c|}{$2006-2008$} & \multicolumn{3}{|c|}{ 2012-2015 } \\
\hline & \multirow{2}{*}{$\begin{array}{c}\text { Débit } \\
10^{5} \mathrm{~m}^{3} / \mathrm{j}\end{array}$} & \multicolumn{2}{|c|}{$\begin{array}{c}\text { Rdt. E } \\
\%\end{array}$} & \multirow{2}{*}{$\begin{array}{l}\text { Débit } \\
10^{5} \mathrm{~m}^{3} / \mathrm{j}\end{array}$} & \multicolumn{2}{|c|}{$\begin{array}{c}\text { Rdt. } \mathrm{E} \\
\%\end{array}$} & \multirow{2}{*}{$\begin{array}{l}\text { Débit } \\
10^{5} \mathrm{~m}^{3} / \mathrm{j}\end{array}$} & \multicolumn{2}{|c|}{$\begin{array}{c}\text { Rdt. E } \\
\%\end{array}$} \\
\hline & & NTK & NGL & & NTK & NGL & & NTK & NGL \\
\hline Seine Aval & 20,8 & 0 & 0 & 17 & 80 & 33 & 15 & 85 & 70 \\
\hline Seine Centre & 2,4 & 95 & 70 & 2,4 & 95 & 70 & 2,4 & 95 & 70 \\
\hline Seine Amont & 3 & 95 & 50 & 6 & 95 & 70 & 6 & 95 & 70 \\
\hline Marne Aval & 0,3 & 75 & 0 & 0,75 & 95 & 70 & 0,75 & 95 & 70 \\
\hline Les Grésillons & 0 & - & - & 1 & 95 & 80 & 3 & 95 & 80 \\
\hline La Morée & 0 & - & - & 0 & - & - & 0,5 & 95 & 70 \\
\hline TOTAL DÉBIT & 26,5 & & & 27,2 & & & 27,7 & & \\
\hline Moy $_{\text {p. }}$ Rdt. E & & 20 & 43 & & 86 & 66 & & 90 & 72 \\
\hline
\end{tabular}


Tableau 4. Flux d'azote nitrifiés $\left(\mathrm{N}=\right.$ tonnage journalier de $\mathrm{NH}_{4}^{+}$nitrifié $)$et dénitrifiés $\left(\mathrm{D}=\right.$ tonnage journalier de $\mathrm{NO}_{3}^{-}$dénitrifié $)$ aux stations d'épuration de l'agglomération parisienne (flux actuels et prévus aux horizons 2006-2008 et 2012-2015). (* Traitement en temps sec).

Table 4. Flows of nitrified nitrogen ( $\mathrm{N}=$ daily nitrified $\mathrm{NH}_{4}^{+}$, in tons $\mathrm{N}$ per day) and denitrified nitrogen $(\mathrm{D}=$ daily denitrified $\mathrm{NO}_{3}$, in tons $\mathrm{Nper}$ day) in the WWTPs of the Paris conurbation, present and future effluent flows as scheduled for 20062008 and 2012-2015. ( ${ }^{*}$ Dry weather treatment).

\begin{tabular}{|c|c|c|c|c|c|c|}
\hline \multirow{3}{*}{ Stations } & \multicolumn{6}{|c|}{ Flux d'azote N (T N/j) } \\
\hline & \multicolumn{2}{|c|}{ Actuel } & \multicolumn{2}{|c|}{$2006-2008$} & \multicolumn{2}{|c|}{$2012-2015$} \\
\hline & $\mathbf{N}$ & D & $\mathbf{N}$ & D & $\mathbf{N}$ & D \\
\hline Seine Aval & 0,0 & 0,0 & 43,2 & 6,4 & 41,0 & 30,4 \\
\hline Seine Centre* & 6,2 & 3,9 & 6,2 & 3,9 & 6,2 & 3,9 \\
\hline Seine Amont & 10,9 & 3,5 & 21,8 & 13,6 & 21,8 & 13,6 \\
\hline Marne Aval & 1,0 & 0,0 & 3,2 & 2,0 & 3,2 & 2,0 \\
\hline Les Grésillons & 0,0 & 0,0 & 3,2 & 2,5 & 9,7 & 7,5 \\
\hline La Morée & 0,0 & 0,0 & 0,0 & 0,0 & 1,7 & 1,1 \\
\hline Total des flux & 18,2 & 7,4 & 77,8 & 28,4 & 83,7 & 58,4 \\
\hline
\end{tabular}

vont être multipliés par un facteur 4 et 4,6 aux horizons 2006-2008 et 2012-2015 respectivement (Total des flux, N, Tableau 4). Les tonnages journaliers de $\mathrm{NO}_{3}{ }^{-}$dénitrifié (D), quasi nuls, voire inexistants sur certaines stations (Tableau 4) vont augmenter d'un facteur 3,8 pour 2006-2008 à 7,9 à partir de 2012. Le traitement de l'azote sera pris en charge en majorité par les stations Seine Aval $(41,0 \mathrm{~T} \mathrm{~N} / \mathrm{j}$ en $\mathrm{N}$ et $30,4 \mathrm{~T} \mathrm{~N} / \mathrm{j}$ en D, 2012-2015, Tableau 4) et Seine Amont (21,8 T N/j en N et 13,6 T N/j en D, 2012-2015, Tableau 4). La nitrification et la dénitrification, au niveau de l'agglomération parisienne, se feront donc en traitement secondaire en boues activées et tertiaire sur cultures fixées.

\section{LES ÉMISSIONS DE $\mathrm{N}_{2} \mathrm{O}$.}

Des études menées sur les émissions de $\mathrm{N}_{2} \mathrm{O}$ issues des différents traitements biologiques de l'azote (traitements secondaires en boues activées et traitements tertiaires sur cultures fixées) appliqués sur les usines d'épuration de l'agglomération parisienne, ont montré qu'elles représentaient de 0,1 à $0,8 \%$ de l'ammonium oxydé ou du nitrate réduit (TALLEC, 2005) (Tableau 5). Ces valeurs varient en fonction de l'oxygénation en traitement secondaire lors de la nitrification et en fonction des quantités de carbone organique exogène (méthanol) ajoutées en traitement tertiaire lors de la dénitrification.

Les émissions de $\mathrm{N}_{2} \mathrm{O}$, provenant des procédés sur cultures fixées en traitement tertiaire lors de la nitrification, se situent dans le haut de la gamme des émissions de $\mathrm{N}_{2} \mathrm{O}$, provenant des procédés avec boues activées en traitement secondaire (Tableau 5). De même lors de la dénitrification, on observe des valeurs d'émission qui peuvent être plus importantes sur cultures fixées (jusqu'à 0,8\% du $\mathrm{NO}_{3}$ - réduit, Tableau 5) qu'en boues activées $\left(0,4 \% \mathrm{du} \mathrm{NO}{ }_{3}^{-}\right.$réduit, Tableau 5$)$. Toutefois, une dénitrification en traitement tertiaire sur cultures fixées peut, lorsque les conditions sont optimales, émettre moins de $\mathrm{N}_{2} \mathrm{O}$ qu'une dénitrification en boues activées lors d'un traitement secondaire.

En considérant les flux d'azote traités (ammonium et nitrate) via la nitrification et la dénitrification pour chaque STEP de l'agglomération parisienne (cf. Tableau 4), nous pouvons calculer (grâce aux valeurs du Tableau 5), le pourcentage de $\mathrm{N} 2 \mathrm{O}$ émis par chacun de ces flux, et donc les quantités actuelles et futures de $\mathrm{N} 2 \mathrm{O}$ émis au niveau de chaque station (Tableau 6).

C'est au niveau de la station Seine Aval que les émissions de $\mathrm{N}_{2} \mathrm{O}$ devraient augmenter le plus d'ici 2006-2008 (Tableau 6), puisque le traitement de l'azote y sera mis en place et que les débits y demeureront les plus élevés, même en tenant compte de leur diminution prévue de 17 à $15 \times 10^{5} \mathrm{~m}^{3} / \mathrm{j}$ (Tableau 3).

Aucun nouveau traitement ou changement de débit n'étant prévu sur la station Seine Centre, les émissions de $\mathrm{N}_{2} \mathrm{O}$ ne devraient pas changer et resteraient à $29-56 \mathrm{~kg}$ $\mathrm{N}-\mathrm{N}_{2} \mathrm{O} / \mathrm{j}$, suivant les quantités de méthanol ajoutées lors de la dénitrification. 
Tableau 5. Pourcentage de $\mathrm{N}_{2} \mathrm{O}$ émis par rapport aux quantités d'azote traitées $\left(\mathrm{NH}_{4}^{+}\right.$oxydé lors de la nitrification et $\mathrm{NO}_{3}^{-}$réduit lors de la dénitrification), suivant le traitement biologique de l'azote utilisé en STEP. Ces données proviennent des études menées sur les différentes stations de l'agglomération parisienne, en boues activées (TALLEC, 2005) et sur cultures fixées (TALLEC, 2005). ('suivant l'oxygénation, ${ }^{* *}$ suivant les quantités ajoutées de méthanol).

Table 5. Percentage of $\mathrm{N}_{2} \mathrm{O}$ emitted per unit of treated nitrogen load ( $\mathrm{NH}_{4}^{+}$oxidized during nitrification and $\mathrm{NO}_{3}^{-}$reduced during denitrification), depending on the biological treatment used in the WWTP. These values are derived from experimental studies on the WWTPs of the Paris conurbation, using activated sludge and fixed culture (TALLEC, 2005). ( Depending on oxygenation, ${ }^{* *}$ depending on the amount of methanol added).

\begin{tabular}{lcc}
\hline & \multicolumn{2}{c}{$\% \mathbf{N}_{2} \mathbf{O} / \mathbf{N}$ éliminé } \\
\cline { 2 - 3 } Systèmes de traitement utilisés & Nitrification & Dénitrification \\
\hline Boues activées en traitement secondaire & $0,1-0,4 \% *$ & $0,4 \%$ \\
Cultures fixées en traitement tertiaire & $0,4 \%$ & $0,1-0,8 \% * *$ \\
\hline
\end{tabular}

Tableau 6. Flux de $\mathrm{N}_{2} \mathrm{O}$ émis via la nitrification $(\mathrm{N})$ et la dénitrification (D) et flux de $\mathrm{N}_{2} \mathrm{O}$ total (N+D : Total) aux stations d'épuration de l'agglomération parisienne : flux actuels et prévus aux horizons 2006-2008 et 2012-2015.

Table 6. Flow of $\mathrm{N}_{2} \mathrm{O}$ emitted during nitrification $(\mathrm{N})$ and denitrification $(D)$ and total $(\mathrm{N}+\mathrm{D}$ : Total) from the WWTPs of the Paris conurbation: present and future effluents flows for the periods 2006-2008 and 2012-2015.

\begin{tabular}{|c|c|c|c|c|c|c|c|c|c|}
\hline \multirow{3}{*}{ Stations } & \multicolumn{9}{|c|}{ Flux $\mathrm{N}_{2} \mathrm{O}(\mathrm{kg} \mathrm{N} / \mathrm{j})$} \\
\hline & \multicolumn{3}{|c|}{ Actuel } & \multicolumn{3}{|c|}{$2006-2008$} & \multicolumn{3}{|c|}{$2012-2015$} \\
\hline & $\mathrm{N}$ & $\mathrm{D}$ & Total & $\mathrm{N}$ & $\mathrm{D}$ & Total & $\mathrm{N}$ & $\mathrm{D}$ & Total \\
\hline Seine Aval & 0 & 0 & 0 & 173 & $6-51$ & $179-224$ & 164 & $30-243$ & $194-407$ \\
\hline Seine Centre & 25 & $4-31$ & $29-56$ & 25 & 04-31 & $29-56$ & 25 & $4-31$ & $29-56$ \\
\hline Seine Amont & $11-44$ & 14 & $25-58$ & $22-87$ & 54 & $76-141$ & $22-87$ & 54 & $76-141$ \\
\hline Marne Aval & 4 & 0 & 4 & 13 & $2-16$ & $15-29$ & 13 & $2-16$ & $15-29$ \\
\hline Les Grésillons & - & - & - & 13 & $3-20$ & $16-23$ & 39 & $8-60$ & $47-99$ \\
\hline La Morée & - & - & - & - & - & - & 7 & $1-9$ & $8-16$ \\
\hline Total émis & \multicolumn{3}{|c|}{$58-118$} & \multicolumn{3}{|c|}{$315-473$} & \multicolumn{3}{|c|}{$369-748$} \\
\hline
\end{tabular}

Lorsque la tranche Valenton I fonctionne seule, la station de Seine Amont présente des flux de $\mathrm{N}_{2} \mathrm{O}$ entre $25-58 \mathrm{~kg}$ $\mathrm{N}-\mathrm{N}_{2} \mathrm{O} / \mathrm{j}$. La mise en route de la nouvelle tranche, Valenton II, traitant le même débit d'eau que Valenton I, mais avec un rendement épuratoire supérieur, augmenterait d'un peu plus du double les quantités de $\mathrm{N}_{2} \mathrm{O}$ émises (Tableau 6, Seine Amont, $25-58$ à 76-141 kg N-N $2 \mathrm{O} / \mathrm{j}$ ).

La station Marne Aval, qui traite actuellement le plus petit débit $\left(0,3 \times 10^{5} \mathrm{~m}^{3} / \mathrm{j}\right.$, Tableau 3), émet évidemment peu de $\mathrm{N}_{2} \mathrm{O}, 4 \mathrm{~kg} \mathrm{~N}-\mathrm{N}_{2} \mathrm{O} / \mathrm{j}$ (Tableau 6). Néanmoins, ses émissions pourraient s'accroître légèrement à l'horizon 2006-2008 (15-29 kg N-N 2 /j, Tableau 6) avec l'augmentation de son débit nominal (Tableau 3) et l'installation d'un traitement de l'azote plus poussé.
La future station des Grésillons devrait émettre du $\mathrm{N}_{2} \mathrm{O}$ en quantité comparable à celle de Marne Aval à l'horizon 2006-2008 (16-23 kg N-N $2 \mathrm{O} / \mathrm{j}$, Tableau 6); à cette station des Grésillons, les émissions devraient être multipliées par un facteur d'environ 3 (47-99 $\left.\mathrm{kg} \mathrm{N}-\mathrm{N}_{2} \mathrm{O} / \mathrm{j}\right)$ en 2012-2015, en même temps que le débit augmentera de 1 à $3 \times 10^{5} \mathrm{~m}^{3} / \mathrm{j}$ (Tableau 6 et Tableau 3).

La Morée, au débit moindre $\left(0,5 \times 10^{5} \mathrm{~m}^{3} / \mathrm{j}\right.$, Tableau 3$)$, devrait être à l'origine d'émissions de $\mathrm{N}_{2} \mathrm{O}$ plus faibles $(8-16 \mathrm{~kg}$ $\mathrm{N}-\mathrm{N}_{2} \mathrm{O} / \mathrm{j}$, Tableau 6).

$\mathrm{Au}$ total, les quantités de $\mathrm{N}_{2} \mathrm{O}$ émises par les stations d'épuration de l'agglomération parisienne devraient augmenter au cours du temps avec la prise en charge de l'élimination de 
l'azote, au niveau de Seine Aval notamment. Ainsi, les émissions actuelles de $\mathrm{N}_{2} \mathrm{O}$ de $58-118 \mathrm{~kg} \mathrm{~N}-\mathrm{N}_{2} \mathrm{O} / \mathrm{j}$, augmenteraient à 315-473 kg N-N $20 / j$ à l'horizon 2006-2008 et atteindraient $369-748 \mathrm{~kg} \mathrm{~N}-\mathrm{N}_{2} \mathrm{O} / \mathrm{j}$ à l'horizon 2012-2015 (Total émis, Tableau 6). De ces estimations, il faut évidemment déduire celles de la basse Seine $\left(90-200 \mathrm{~kg} \mathrm{~N}-\mathrm{N}_{2} \mathrm{O} / \mathrm{j}\right)$ qui seront largement déplacées vers les stations, ainsi que le montrent les simulations par le modèle du fonctionnement écologique du bassin de la Seine (GARNIER et al., sous presse).

\section{DISCUSSION}

\subsection{Les émissions de $\mathrm{N}_{2} \mathrm{O}$ provenant des traitements tertiaires sur cultures fixées et des traitements secondaires en boues activées}

Le pourcentage de $\mathrm{N}_{2} \mathrm{O}$ émis par rapport aux flux d'azote traités est présenté ici avec une certaine variabilité (Tableau 5), prenant en compte les principaux facteurs pouvant influencer directement les émissions d'oxyde nitreux lors du traitement, tels que l'oxygène et le carbone organique (HANAKI et al., 1990; ITOKAWA et al., 2001; PATHAK, 1999).

Nos travaux expérimentaux (TALLEC, 2005; TALLEC et al., 2006) ont montré que, d'une manière générale, les émissions de $\mathrm{N}_{2} \mathrm{O}$ sur cultures fixées en traitement tertiaire se situaient dans la gamme haute de celles issues des traitements secondaires en boues activées. Nous avons, en outre, montré que les émissions de $\mathrm{N}_{2} \mathrm{O}$, provenant d'un traitement secondaire en boues activées, étaient directement influencées par l'oxygénation, lors de la nitrification ou de la dénitrification (TALLEC, 2005).

Lors de la nitrification, les émissions de $\mathrm{N}_{2} \mathrm{O}$ les plus importantes sont observées lorsque l'oxygénation se situe autour de $1 \mathrm{mg} \mathrm{O} / \mathrm{L}$ (CÉBRON et al., 2005; TALLEC, 2005; TALLEC et al., 2006; ZHENG et al., 1994). Le pic d'émission, dû au processus de nitrification-dénitrifiante, est réalisé par les bactéries autotrophes, où l'oxydation du $\mathrm{NH}_{4}^{+}$en $\mathrm{NO}_{2}{ }^{-}$est suivie par une réduction du $\mathrm{NO}_{2}^{-}$en $\mathrm{N}_{2} \mathrm{O}$ et $\mathrm{N}_{2}$ (BOCK et al., 1995; ITOKAWA et al., 2001; JIANG et BAKKEN, 1999; KUAI et VERSTRAETE, 1998). Les bactéries ammonium-oxydantes sont capables de réaliser une nitrification dénitrifiante lorsque l'oxygène est limitant, le nitrite remplaçant l'oxygène comme accepteur d'électron final (SHRESTHA et al., 2002; TALLEC, 2005).

Un même pic d'émissions de $\mathrm{N}_{2} \mathrm{O}$ se produit lors de la dénitrification en traitement secondaire avec un bassin anoxique en tête de filière, à environ $0,3 \mathrm{mg} \mathrm{O}_{2} / \mathrm{L}$, surtout si le bassin n'est pas couvert, ce qui permet ainsi à basse température une oxygénation (TALLEC, 2005). Même si le $\mathrm{N}_{2} \mathrm{O}$ n'est généralement qu'un intermédiaire de la dénitrification, des organismes capables de produire du $\mathrm{N}_{2} \mathrm{O}$ en phase finale de la dénitrification ont été caractérisés (BRETTAR et HÖFLE, 1993; GREENBERG et BECKER, 1977). D'autres travaux ont également montré qu'à de faibles concentrations en oxygène (toutefois pas mentionnées), le $\mathrm{N}_{2} \mathrm{O}$ peut être le produit final de la dénitrification au lieu du $\mathrm{N}_{2}$ (ROBERTSON et al., 1995; BAUMANN et al., 1996), la réductase de l'oxyde nitreux étant l'enzyme la plus sensible à l'oxygène (BONIN et al., 1989).

Les émissions de $\mathrm{N}_{2} \mathrm{O}$ provenant des systèmes de traitement tertiaire présentent une large variabilité lors de la dénitrification (Tableau 5), conditionnée par les ajouts de carbone organique. Ainsi, les émissions d'oxyde nitreux les plus faibles $(0,1 \%$ du nitrate dénitrifié) sont observées lorsque les quantités de méthanol ajoutées permettent au moins $100 \%$ de la dénitrification, alors qu'entre 50 et $80 \%$ de la dénitrification, ces émissions sont plus importantes $(0,8 \% \mathrm{du}$ nitrate dénitrifié), (TALLEC, 2005).

\subsection{Bilan des émissions de $\mathrm{N}_{2} \mathrm{O}$ sur les stations d'épuration de l'agglomération parisienne}

Des estimations de $\mathrm{N}_{2} \mathrm{O}$, à partir de données acquises in situ sur les quatre stations de l'agglomération parisienne, sur les différents systèmes de traitement de l'azote, mais aussi du carbone, conduisent à des valeurs de l'ordre de $200 \mathrm{~kg}$ $\mathrm{N}-\mathrm{N}_{2} \mathrm{O} / \mathrm{j}$ pour l'ensemble du traitement actuel des eaux usées (LEGAIGNEUR, 2003). Ces estimations sont du même ordre de grandeur, à un facteur 2 près, que celles que nous calculons pour le seul traitement actuel $\left(58-118 \mathrm{~kg} \mathrm{~N}-\mathrm{N}_{2} \mathrm{O} / \mathrm{j}\right)$.

SÜMER et al. (1995) et THÖRN et SÖRENSEN (1996) trouvent respectivement une production d'oxyde nitreux en boues activées de l'ordre de $0,22 \mathrm{~g} \mathrm{~N}-\mathrm{N}_{2} \mathrm{O} / \mathrm{m}^{3} / \mathrm{j}$ en dénitrification et de $0,02 \mathrm{~g} \mathrm{~N}-\mathrm{N}_{2} \mathrm{O} / \mathrm{m}^{3} / \mathrm{j}$ en nitrification, soit un total de $0,24 \mathrm{~g} \mathrm{~N}-\mathrm{N}_{2} \mathrm{O} / \mathrm{m}^{3} / \mathrm{j}$ pour l'ensemble du traitement de l'azote. Pour un total de $27,7 \times 10^{5} \mathrm{~m}^{3} / \mathrm{j}$ d'eaux usées de l'agglomération parisienne, qui subiront un traitement de la pollution azotée, via la dénitrification et la nitrification en 2012-2015, nous pouvons, d'après ces auteurs, estimer des émissions de $\mathrm{N}_{2} \mathrm{O}$ de l'ordre de $700 \mathrm{~kg} \mathrm{~N} / \mathrm{j} \quad(0,24 \mathrm{~g}$ $\mathrm{N}-\mathrm{N}_{2} \mathrm{O} / \mathrm{m}^{3} / \mathrm{j} \times 27,7 \times 10^{5} \mathrm{~m}^{3} / \mathrm{j}$ ). Ces valeurs correspondent également bien à celles estimées ici pour cette période, soit 369-748 kg N- $\mathrm{N}_{2} \mathrm{O} / \mathrm{j}$. Nos estimations des émissions de $\mathrm{N}_{2} \mathrm{O}$, au niveau des stations d'épuration de la région parisienne, sont donc confortées par celles provenant de sources très différentes.

Toutes ces estimations sont basées sur des expériences effectuées sur les boues activées et cultures fixées des stations de l'agglomération parisienne, dans leur état propre, in situ. Si les émissions de $\mathrm{N}_{2} \mathrm{O}$ peuvent changer d'une station à l'autre, ces variations peuvent en plus être modulées par les configurations utilisées par l'exploitant de la station, c.-à-d. celles relatives à 
l'oxygénation et aux quantités ajoutées de méthanol (TALLEC, 2005). Ces émissions peuvent également varier en fonction des contraintes climatiques (temps de pluie, temps sec), hydrologiques, etc. Les valeurs fournies ici présentent ainsi une variabilité que l'exploitant peut mettre à profit pour réduire les émissions de $\mathrm{N}_{2} \mathrm{O}$, tout en optimisant le traitement des effluents.

\subsection{Impact des émissions de $\mathrm{N}_{2} \mathrm{O}$ provenant des stations d'épuration de l'agglomération parisienne, actuelles et futures sur le bassin de la Seine}

De manière générale, les émissions de $\mathrm{N}_{2} \mathrm{O}$ sur l'ensemble des stations de l'agglomération parisienne, ne dépassent actuellement pas plus de $120 \mathrm{~kg} \mathrm{~N}-\mathrm{N}_{2} \mathrm{O} / \mathrm{j}$. Il faut y ajouter les émissions de la basse Seine, liées à la nitrification et la dénitrification des effluents rejetés par l'agglomération parisienne, environ $120 \mathrm{~kg} \mathrm{~N}-\mathrm{N}_{2} \mathrm{O} / \mathrm{j}$ pour l'aval de l'agglomération parisienne $\left(90-200 \mathrm{~kg} \mathrm{~N}-\mathrm{N}_{2} \mathrm{O} / \mathrm{j}\right.$; GARNIER et al., 2006), soit un total d'environ $240 \mathrm{~kg} \mathrm{~N}-\mathrm{N}_{2} \mathrm{O} / \mathrm{j}$.

Avec un meilleur traitement de l'azote en station d'épuration, les émissions de $\mathrm{N}_{2} \mathrm{O}$ seraient au total à peine plus élevées en 2006-2008 compte tenu des incertitudes, soit $315-473 \mathrm{~kg} \mathrm{~N}-\mathrm{N}_{2} \mathrm{O} / \mathrm{j}$ mais renforcées à 369-748 kg N-N $2 \mathrm{O} / \mathrm{j}$ en 2012-2015, lors de la mise en place d'une dénitrification totale au niveau de la station Seine Aval.

Une augmentation des émissions de $\mathrm{N}_{2} \mathrm{O}$ avec une nitrification et une dénitrification réalisées en station d'épuration, et non plus dans le milieu naturel, pourrait s'expliquer par des différences de communautés bactériennes. Il a été en effet montré que toutes les espèces bactériennes n'émettaient pas les mêmes quantités de $\mathrm{N}_{2} \mathrm{O}$ (ANDERSON et al., 1993; CAVIGELLI et ROBERTSON, 2001). En outre, les travaux de CÉBRON et al. (2003) ont mis en évidence des différences entre les communautés bactériennes nitrifiantes en provenance de la station Seine Aval et celles au niveau de l'estuaire.

Si le traitement des eaux usées, via l'élimination de la pollution azotée, peut être considéré comme à l'origine d'une nouvelle source de pollution potentiellement importante pour l'environnement, le $\mathrm{N}_{2} \mathrm{O}$ étant un gaz à effet de serre actif, il est important de resituer cette pollution atmosphérique à l'échelle régionale du bassin. En effet, les émissions par les STEPs seraient relativement faibles, et plus par rapport aux émissions provenant des sols agricoles du bassin amont (4 100-8 $200 \mathrm{~kg}$ $\mathrm{N}-\mathrm{N}_{2} \mathrm{O} / \mathrm{j}$, GARNIER et al., 2006 sur la base des travaux de KHALIL et al., 2004, soit 1 à $10 \%$ ) qu'en regard de celles de l'ensemble du réseau hydrographique de la Seine (370-680 kg $\mathrm{N}-\mathrm{N}_{2} \mathrm{O} / \mathrm{j}$, GARNIER et al., 2006, de l'ordre 20 à $\left.100 \%\right)$. À noter que les estimations des émissions dans le bassin ne prennent pas en compte celles des zones ripariennes, encore difficiles à quantifier.

Si le traitement de l'azote en station d'épuration est susceptible d'accroître les émissions de gaz à effet de serre tel que le $\mathrm{N}_{2} \mathrm{O}$, une réduction poussée des rejets d'azote dissous dans le milieu naturel par les stations d'épuration devrait toutefois permettre de limiter les problèmes d'eutrophisation côtière (cf. CUGIER et al., 2005). En absence d'une réduction à la source des intrants azotés (fertilisants agricoles), il apparaît donc nécessaire de contrôler au mieux les processus de nitrification et de dénitrification impliqués dans les traitements tertiaires en stations d'épuration.

\section{REMERCIEMENTS}

Ce travail a été effectué dans le cadre des programmes du PIREN-Seine et de Seine-Aval. L'étude a été financée par le Syndicat Interdépartemental pour l'Assainissement de l'Agglomération Parisienne (SIAAP).

\section{RÉFÉRENCES BIBLIOGRAPHIQUES}

ANDERSON IC., M. POTH, J. HOMSTEAD et D. BURDIGE (1993). A comparison of $\mathrm{NO}$ and $\mathrm{N}_{2} \mathrm{O}$ production by the autotrophic nitrifier Nitrosomonas europea and the heterotrophic nitrifier Alcaligenes faecalis. Appl. Environ. Microbiol., 59, 3525-3533.

BAUMANN B., M. SNOZZI, A.J.B. ZEHNDER et J.R. VAN DER MEER (1996). Dynamics of denitrification activity of Paracoccus denitrificans in continuous culture during aerobic-anaerobic changes. J. Bacteriol., 178, 4367-4374.

BILLEN G., J. GARNIER, A. FICHT et C. CUN (2001). Modeling the response of water quality in the Seine River Estuary to human activity in its watershed over the last 50 years. Estuaries, 24, 977-993.

BLIEFERT C. et R. PERRAUD (2001). Les oxydes d'azote. Dans : Chimie de l'environnement, air, eau, sol, déchets. DE BOECK (Éditeurs), Paris, pp. 177-188.

BOCK. E., E. SCHMIDT, R. STÜVEN et D. ZART (1995). Nitrogen loss caused by denitrifying Nitrosomonas cells using ammonium or hydrogen as electron donors and nitrite as electron acceptor. Arch. Microbiol., 163, 16-20.

BONIN P., M. GILEWIEZ et J.C. BERTRAND (1989). Effect of oxygen on each step of denitrification on Pseudomonas nautica strain 617. Can. J. Microbiol., 35, 1061-1064. 
BRETTAR I. et M.G. HÖLFE (1993). Nitrous oxide producing heterotrophic bacteria from water column of the central Baltic: abundance and molecular identification. Mar. Ecol. Prog. Ser., 94, 253-265.

BRION N., G. BILLEN, L. GUEZENNEC et A. FICHT (2000). Distribution of nitrifying activity in the Seine River (France) from Paris to the estuary. Estuaries, 23, 669-682.

CAVIGELLI M.A. et G.P. ROBERTSON (2001). Role of denitrifier diversity in rates of nitrous oxide consumption in a terrestrial ecosystem. Soil Biol. Biochem., 33, 297-310.

CÉBRONA.,T. BERTHE et J. GARNIER (2003). Nitrification and nitrifying bacteria in the lower Seine River and estuary. Appl. Environ. Microbiol., 69, 7091-7100.

CÉBRON A., J. GARNIER et G. BILLEN (2005). Nitrous oxide production and nitrification kinetics by bacteria communities naturally present in river water (the lower Seine, France). Aquat. Microb. Ecol., 41, 25-38.

\section{CITEPA (CENTRE INTERPROFESSIONNEL} TECHNIQUE D'ÉTUDES DE LA POLLUTION ATMOSPHÉRIQUE) (2003). Émissions dans l'air en France métropole. Comparaisons des émissions de la France et d'autres pays. www.citepa.org/France-autres/ comparaisons.pdf, consulté le 15 février 2003.

CUGIER PH., G. BILLEN, J.F. GUILLAUD, J. GARNIER et A. MÉNESGUEN (2005). Modeling the eutrophication of the Seine Bight (France) under historical. present and future riverine nutrient loading. J. Hydrol., 304, 381-396.

GARNIER J., B. LEPORCQ, N. SANCHEZ et X. PHILIPPON (1999). Biogeochemical mass balances (C. N. P. Si) in the three large reservoirs of the seine basin (France). Biogeochem., 47, 119-146.

GARNIER J., G. BILLEN, N. SANCHEZ et B. LEPORCQ (2000). Ecological functioning of the Marne reservoir (upper Seine basin, France). Regul. Rivers Res. Manage., 16, 51-71.

GARNIER J., P. SERVAIS, G. BILLEN, M. AKOPIAN et N. BRION (2001). Lower Seine river and estuary (France): carbon and oxygen budgets during low flow. Estuaries, 24, 964-976.

GARNIER J., A. CÉBRON, G. TALLEC, G. BILLEN, M. SEBILO et A. MARTINEZ (2006). Nitrous oxide emission in the Seine River estuary (France): comparison with upstream sector of the Seine basin. Biogeochem., 77, 305-326.
GARNIER J., A. CÉBRON et G. BILLEN (sous presse). Modeling nitrogen transformations in the lower Seine river and estuary (France): impact of wastewater release on oxygenation and $\mathrm{N}_{2} \mathrm{O}$ emission. Hydrobiol.

GOREAU T.J., W. KAPLAN, S. WOFSY, M. McELROY, F. VALOIS et S. WATSON (1980). Production of $\mathrm{NO}_{2}{ }^{-}$and $\mathrm{N}_{2} \mathrm{O}$ by nitrifying bacteria at reduced concentrations of oxygen. Appl. Environ. Microbiol., 40, 526-532.

GREENBERG E.P. et G.E. BECKER (1977). Nitrous oxide as end product of denitrification by strains of fluorescent Pseudomonas. Can. J. Microbiol., 23, 903-907.

HANAKI K., C. WANTAWIN et S. OHGAKI (1990). Nitrification at low levels of dissolved oxygen with and without organic loading in a suspended-growth reactor. Water Res., 24, 297-302.

HANAKI K., Z. HONG et T. MATSUO (1992). Production of nitrous oxide gas during denitrification of wastewater. Water Sci. Technol., 26, 1027-1036.

IPCC (INTERGOVERNMENTAL PANEL ON CLIMATE CHANGE)(2000). Special report on emissions scenarios; Univ. Press, Cambridge, 598 p.

ITOKAWA H., K. HANAKI et T. MATSUO (2001). Nitrous oxide production in high-loading biological nitrogen removal process under low $\mathrm{COD} / \mathrm{N}$ ratio condition. Water Res., 35, 657-664.

JIANG Q-Q. et L.R. BAKKEN (1999). Nitrous oxide production and methane oxidation by different ammoniaoxidizing bacteria. Appl. Environ. Microbiol.,65, 2679-2684.

KHALIL K., B. MARY et P. RENAULT (2004). Nitrous oxide production by nitrification and denitrification in soil aggregates as affected by $\mathrm{O}_{2}$ concentration. Soil Biol. Biochem., 36, 687-699.

KIM J.S., S.J. KIM et B.H. LEE (2004). Effect of Alcaligenes faecalis on nitrous oxide emission and Nitrogen removal in three phase fluidized bed process. J. Environ Sci. Health, 39, 1791-1804.

KNOWLES R. (1982). Denitrification. Microbiol. Rev., 46, 43-70.

KUAI L. et W. VERSTRAETE (1998). Ammonium removal by the oygen-limited autotrophic nitrification-denitrification system. Appl. Environ. Microbiol., 64, 4500-4506. 
LEGAIGNEUR V. (2003). Émissions atmosphériques provenant des stations d'épuration du SIAAP, en particulier les oxydes d'azote et le protoxyde d'azote. Diplôme de recherche technologique. Univ. Paris 7, 178 p.

PATHAK H. (1999). Emissions of nitrous oxide from soil. Curr. Sci., 77, 359-369.

POTH M. et D. FOCHT (1985). $15 \mathrm{~N}$ kinetic analysis of $\mathrm{N}_{2} \mathrm{O}$ production by Nitrosomonas europaea: an examination of nitrifier denitrification. Appl. Environ. Microbiol., 49, 1134-1141.

ROBERTSON L.A., T. DALSGAAR, N.P. REVSBECH et J.G. KUENEN (1995). Confirmation of aerobic denitrification in batch cultures, using gas chromatography and $15 \mathrm{~N}$ mass spectrometry. FEMS Microbiol. Ecol., 18, 113-120.

SHRESTHA N., S. HADANO, T. KAMACHI et I. OKURA (2002). Dinitrogen production from ammoia by Nitrosomonas europaea. Appl. Catal. A Gen., 237, 33-39.

SÜMER L.Y., A. WEISKE, G. BENCKISER et J.C.G. OTTOW (1995). Influence of environmental conditions on the amount of $\mathrm{N}_{2} \mathrm{O}$ released from activated sludge in a domestic wastewater treatment plant. Experientia, 51, 419-422.

TALLEC G. (2005). Émissions d'oxyde nitreux lors du traitement de l'azote en station d'épuration. Thèse de doctorat, ENPC, ED «Ville et Environnement», Paris, $253 \mathrm{p}$.

TALLEC. G., J. GARNIER, G. BILLEN et M. GOUSAILLES (2006). Nitrous oxide emissions from secondary activated sludge in nitrifying conditions of urban wastewater treatment plants: effect of oxygenation level. Water Res., 40, 2972-2980.

THÖRN M. et F. SÖRENSEN (1996). Variation of nitrous oxide formation in the denitrification basin in a wastewater treatment plant with nitrogen removal. Water Res., 30, 1543-1547.

TUSSEAU-VUILLEMIN M.H., G. LE REVEILLÉ, J.M. MOUCHEL, J. DISPAN, M. DELBEC et P. SERVAIS (2000). Biodégradabilité de la matière organique en sortie de la station d'épuration, Paris, France. Rapport d'activité Piren-Seine, 1999, 4-22.

ZHENG H., K. HANAKI et T. MATSUO (1994). Production of nitrous oxide gas during nitrification of wastewater. Water Sci. Technol., 30, 134-141. 